\title{
Elevated Levels of Serum Ferritin May be Related to Non-Alcoholic Steatohepatitis
}

\section{Yüksek Serum Ferritin Düzeyleri Alkolik Olmayan Steatohepatit ile Ilgili Olabilir}

Mohamed Abdel-Halem Helaly ${ }^{1}$, El-Sayed Zaki Hatata ${ }^{1}$, Ehab El-Sayed Abdel-Khalek ${ }^{1}$, Ibrahim Ahmed Abdel Aal2

Mansoura University, Faculty of Medicine, Departements of Internal Medicine ${ }^{1}$ and Clinical Pathology ${ }^{2}$, Egypt

Eur J Basic Med Sci 2011;1(1):13-20

Received: 31.08 .2010

Accepted: 27.09.2010
Correspondence (Yazıșma Adresi):

Mohamed A. Helaly,

Specialized Medical Hospital, Departement of Internal Medicine, 35516, Al-Gomhoria Street, Mansoura, Dakahlia Governorate, Egypt

Phone: 0020162216791

E-mail: helaly70@yahoo.com

European Journal of Basic Medical Sciences

\begin{abstract}
Non-alcoholic steatohepatitis can progress to cirrhosis and hepatocellular carcinoma. Our aim is to evaluate serum ferritin and iron levels in patients with non-alcoholic steatohepatitis (NASH). 53 patients with NASH (36 males and 17 females) were selected from the Specialized Medical Hospital, Mansoura, Egypt. This is in addition to 50 apparently healthy subjects (30 males and 20 females) of age and sex matched as a control group. We detected serum ferritin, iron, immune-reactive insulin (IRI) and the calculated homeostasis model for assessment of insulin resistance (HOMA-IR), in addition to markers of oxidative stress (MDA and thiol) and tumor necrosis factor alpha (TNF-a). Patients with NASH have higher levels of ferritin, iron, IRI, HOMA-IR, MDA, TNF- $a(p=0.001)$ and thiol $(p=0.01)$ than control subjects. Serum ferritin has a significant positive correlation with body mass index, ALT, AST, fasting plasma glucose (FPG), total cholesterol, LDL-cholesterol, triglyceride, IRI, HOMA-IR, MDA, thiol and TNF- $a(p=0.001)$ in NASH patients. However, after adjustment for age, sex, BMI and HOMA-IR in cases of NASH, ferritin still has a significant positive correlation with ALT, FPG, total cholesterol, TNF- $a$, MDA $(p=0.001)$ and thiol $(p=0.003)$. Serum iron has no significant correlation with grade of $\mathrm{NASH}$ or fibrosis. Serum ferritin level is higher in patients with NASH more than control subjects. Moreover it has a significant positive correlation with oxidative stress even after adjustment for age, sex, BMI and HOMA-IR.
\end{abstract}

Key words: Ferritin, non-alcoholic, steatohepatitis 


\section{ÖZET}

Alkolik olmayan steatohepatit (NASH) siroza veya hepatoselüler karsinoma ilerleyebilir. Amacımı hastalarda serum ferritin ve demir seviyelerini değerlendirmektir. NASH'li 53 hasta (36 erkek and 17 kadın) Mansoura, Mısır'daki özel hastaneden seçildi. Buna 50 sağlıklı görünen kiși (30 erkek and 20 kadın) kontrol grubu olarak eklendi. Serum ferritin, demir, immün-reaktif insülin (IRI) tespit edildi ve insulin rezistansI değerlendiren hesaplanmış homestaz modeli (HOMA-IR), buna ilaveten oksidatif stress belirteçleri (MDA ve tiol) ve tümör nekroz faktör alfa (TNF-a). NASH'lı hastaların ferritin, iron, IRI, HOMA-IR, MDA $(p=0.001)$, TNF- $a(p=0.001)$ ve tiol $(p=0.003)$ düzeyleri kontrollerden daha yüksekti. NASH'lı hastalarda serum ferritinin vücut kitle indeksiyle, AST, ALT, açlik plazma glikozu (FPG), total kolesterol, LDL-kolesterol, trigliserid, IRI, HOMA-IR, MDA, tiol ve TNF-a, belirgin pozitif korelasyon vardı. Serum demir NASH derecelemesinde ve fibrozla korelasyon göstermediler. Serum ferritin düzeyleri NASH'l hastalarda daha yüksekti. Daha ötesi, oksidatif stresle yaş, cinsiyet, VKi ve HOMA_IR yüksek pozitif korelasyon mevcuttu.

Anahtar Kelimeler: Ferritin, Alkolik olmayan, steatohepatit

\section{INTRODUCTION}

Non-alcoholic fatty liver disease (NAFLD) is a clinical condition that comprises a wide spectrum of liver damage, ranging from simple steatosis to steatohepatitis, advanced fibrosis and cirrhosis in patients with normal or elevated serum alanine transaminase enzyme (ALT) (1). NAFLD and non- alcoholic steatohepatitis (NASH) are highly prevalent diseases, and is estimated that a quarter of the adult population currently has NAFLD. Furthermore, 20-30\% of patients with NAFLD will develop NASH that may progress to cirrhosis, end stage liver disease and hepatocellular carcinoma (2).

In 1980, Ludwig et al (3) coined the term non-alcoholic steatohepatitis. The diagnosis of NASH is based solely on the liver histopathologic features which include macrovesicular steatosis, lobular inflammation, hepatocyte degeneration or ballooning and $\square$ or hepatic fibrosis (4). It is suggested that there are multiple pathogenic mechanisms underlying NASH including insulin resistance (5), oxidative stress (6) and cytokine production (7). However, the role of iron and ferritin in the pathogenesis of NASH is still controversial and not yet established. Kemal et al
(8) said that there is no correlation between hepatic iron and the development of NASH. Other studies implicate serum ferritin (9) and hepatic iron concentration (10) in the pathogenesis of NASH.

The aim of this study is to evaluate serum ferritin and iron levels in patients with NASH and the correlations of serum ferritin with insulin resistance and oxidative stress and the correlation of serum iron with grade of NASH and fibrosis.

\section{MATERIALS AND METHODS}

\section{Patients}

53 patients who were diagnosed having NASH on the basis of liver biopsy ( 36 males and 17 females) according to Brunt et al for grading/ staging system for NASH (11) were selected from 100 patients having bright liver on abdominal ultrasound examination together with elevated liver enzymes. They were taken from the outpatient and inpatient sections of internal medicine department, Specialized Medical Hospital, Mansoura, Egypt. All patients gave written informed consent before participation in the study. Control group was formed from 50 apparently healthy age and sex matched subjects (30 males and 20 females). They have undergone the following: Through history taking with special stress on symptoms suggestive of chronic liver diseases, history of drug intake that may affect the liver like amiodarone, tamoxifen and contraceptive pills.

Full physical examination was performed including measurement of weight, height and body mass index (BMI), systolic and diastolic blood pressures (SBP and DBP, respectively), abdominal examination with stress on hepatosplenomegaly and ascites in addition to examination of the other systems of body. Abdominal ultrasonographic procedures were carried on to detect fatty liver and exclusion of other hepatic or abdominal problems and for ultrasound guided liver biopsy for diagnosis and grading of NASH.

Patients with history of alcohol and hepatotoxic drugs intake and jaundice following drug intake, with positive serology for hepatitis B or C virus infection or with autoimmune hepatitis or primary biliary cirrhosis, Willson's syndrome, hemachromatosis, decompensate liver cirrhosis who exhibited ascites, jaundice or hepatic encephalopathy, hepatocellular carcinoma, major cardiac 
Table 1. Comparison of the demographic characteristics and laboratory findings of the patient and control groups

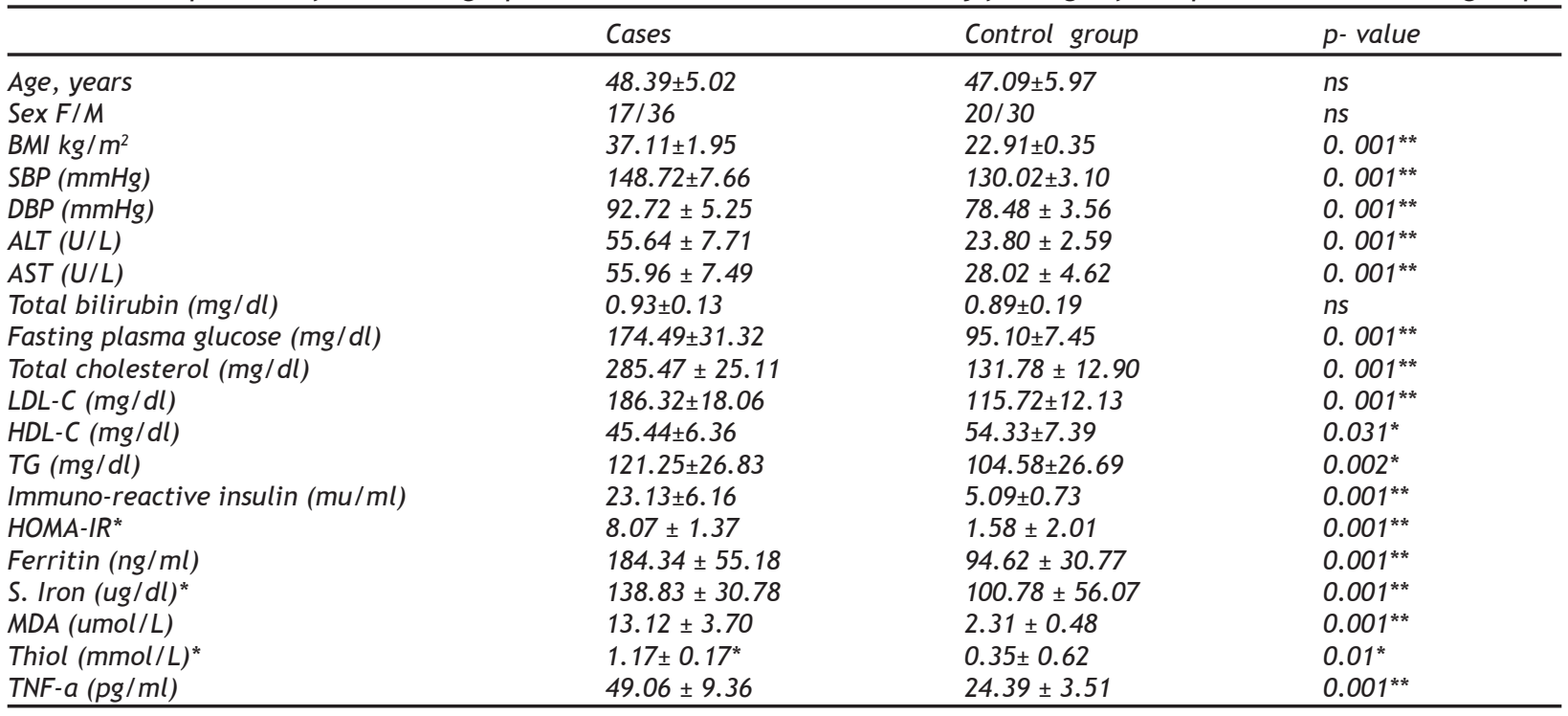

ALT: alanine aminotransferase , AST: aspartate aminotransferase ,BMI: body mass index, DBP: diastolic blood pressure, HDL-C : high density lipoprotein-cholesterol , HOMA-IR: homeostasis model for assessment of insulin resistance, LDL-C: low density lipoprotein-cholesterol , MDA: malondialdehyde, ns: non-significant, SBP: systolic blood pressure, TG: triglyceride, TNF-a: tumor necrosis factor alpha. * Mann-Whitney for non-parametric tests was applied for HOMA-IR, Iron \& Thiol.

and pulmonary diseases, uremia or inflammatory conditions (total leucocyte count above $8000 / \mathrm{mm} 3$ ), hyperthyroidism, anemia, hemolysis, recent blood transfusion and recent iron therapy were excluded from the study.

\section{Method}

Routine laboratory tests including liver function tests (liver enzymes -ALT and AST-, serum total bilirubin, albumin, prothrombin time and INR), complete blood count $(C B C)$, fasting plasma glucose (FPG) and fasting lipid profile including serum total cholesterol, triglyceride (TG), low density lipoprotein cholesterol (LDL-C) and high density lipoprotein cholesterol (HDL-C) were performed. We have also determined serum ferritin, iron, immune-reactive insulin (IRI) and calculated homeostasis model for assessment of insulin resistance (HOMA-IR), in addition to markers of oxidative stress -malondialdehyde (MDA) and total thiol- and tumor necrosis factor-alpha (TNF-a). Serum ceruloplasmin, antinuclear antibody, antismooth muscle antibody and antimitochondrial antibody were measured for exclusion of cases of Wilson's syndrome, autoim mune diseases of the liver and primary biliary cirrhosis (PBC), respectively.
We have 23 type 2 diabetic patients according to the criteria of the American Diabetes Association for diagnosis of diabetes as fasting blood glucose is equal to or more than $126 \mathrm{mg} \square \mathrm{dl}(12)$. Diabetic patients in this study population were controlled with diet regimen.

\section{Laboratory analysis}

Fasting blood samples were collected from each subject, incubated at $37^{\circ} \mathrm{C}$. After centrifugation at 3000 rpm for 15 minutes, serum samples were separated and kept at $-80^{\circ} \mathrm{C}$ in aliquots until the time of assay.

Analysis of triglyceride was performed according to the method of Wahlefeld (13), and total cholesterol according to Allian et al (14). HDL-C determinations were due to Bachrik and Alerbs (15) and LDL-C contents were calculated according to the Friedewald formula (LDL-C= Total cholesterol - (TG/5 + HDL-C). Serum total thiol levels were estimated by spectrophotometric assay described by $\mathrm{Hu}$ (16) and lipid peroxidation product (MDA) was measured in serum using thiobarbituric acid (TBA) assay desribed by Draper and Hadley (17). Serum ferritin was measured by a particle-enhanced immunoturbidimetric assay using the Hitachi 911 analyzer (Roche Diagnostics, Basle, Switzerland). Serum insulin levels were assayed by a specific enzyme linked immune sorbent assay 
Table 2. Correlation analysis of serum ferritin with other parameters in patients with NASH

\begin{tabular}{lll}
\hline & $r$ & $p$ value \\
\hline BMI & 0.54 & $0.001^{* *}$ \\
Total bilirubin & 0.041 & $\mathrm{~ns}$ \\
ALT & 0.73 & $0.001^{* *}$ \\
AST & 0.91 & $0.001^{* *}$ \\
Fasting plasma glucose & 0.98 & $0.001^{* *}$ \\
Total cholesterol & 0.43 & $0.001^{* *}$ \\
TG & 0.92 & $0.001^{* *}$ \\
HDL-C & 0.2 & $\mathrm{~ns}$ \\
LDL-C & 0.88 & $0.001^{* *}$ \\
MDA & 0.97 & $0.001^{* *}$ \\
Thiol & 0.95 & $0.001^{* *}$ \\
Immuno-reactive insulin & 0.95 & $0.001^{* *}$ \\
HOMA-IR & 0.94 & $0.001^{* *}$ \\
TNF- $a$ & 0.95 & $0.001^{* *}$ \\
\hline
\end{tabular}

(ELISA) using kits obtained from Bio-Source-Europe S.A (8rue DEL, Industries, D-1900, Nivelles, Belgium) and the tests were performed according to manufacturer's instructions. HOMA-IR was calculated with the following equation: HOMA-IR= Fasting Plasma Glucose (FPG) (mg/ $\mathrm{dl}) \times$ Immune Reactive Insulin (IRI) (u $\mathrm{u} \mathrm{ml}) \div 405$ (18). Serum TNF- a was measured using a commercially available immunoassay (ELISA kit, Quantikine, R\&D Systems, USA) according to the manufacturer instructions.

\section{Statistical analysis}

The statistical analysis of the data was done using SPSS (Statistical Package of Social Science) Program version 10. The data was presented in the form of mean \pm standard deviation for quantitative data and frequency and proportion for qualitative data. For comparison of statistical significance between two groups t-test was used. For qualitative data, Chi-square test was used. Mann-Whitney test was applied for HOMA-IR, iron and thiol because their values showed non-parametric distribution. Pearson correlation analyis was used to study correlation between variables. Linear regression analysis for the correlation of serum ferritin with the other variables after the adjustment for age, sex, $\mathrm{BMI}$ and HOMA-IR was done. Confusing variables in this case control study were the age, sex, BMI and HOMAIR. Significance was considered when the $p$ value is less than 0.05 at a confidence interval $95 \%$.

\section{RESULTS}

The levels of BMI, SBP, DBP, ALT, AST, FPG, total cholesterol, LDL-C and TG in patients with NASH were significantly higher than in control subjects. However, the levels of HDL-C were significantly lower in the patient group. Moreover, the levels of IRI, HOMA-IR, ferritin, iron, MDA, total thiol and TNF-a were significantly higher in cases of NASH than in control subjects. No significant difference in age or sex between cases and control subjects was noted (Table 1). In cases of NASH there was a significant positive correlation of ferritin with BMI, ALT, AST, FPG, TC, TG, LDL-C, MDA, thiol, IRI, HOMA-IR and TNF-a. However, there was no significant correlation of ferritin with total bilirubin or HDL-C (Table 2). After adjustment for age, sex, BMI and HOMA-IR, ferritin still presented a significant positive correlation with ALT, FPG, total cholesterol, MDA, thiol and TNF-a. However, there was no significant correlation of ferritin with total bilirubin, AST, HDL-C, LDL-C or TG (Table 3). Serum iron

Table 3. Correlation analysis of serum ferritin with other parameters in patients with NASH after adjustment of age, sex, BMI \& HOMA-IR

\begin{tabular}{lllll}
\hline Variable & B & Beta & $95 \%$ C. I. & p value \\
\hline Total bilirubin & 28.107 & 0.043 & $-49.21,105.425$ & $\mathrm{~ns}$ \\
AST & 2.034 & 0.544 & $0.913,3.155$ & $\mathrm{~ns}$ \\
ALT & 3.135 & 0.758 & $2.122,4.149$ & $0.001^{* *}$ \\
Fasting plasma glucose & 1.468 & 1.063 & $1.257,1.678$ & $0.001^{* *}$ \\
Total cholesterol & 0.041 & 0.051 & $0.26,0.344$ & $0.001^{* *}$ \\
LDL-C & 1.265 & 0.769 & $0.754,1.775$ & $\mathrm{~ns}$ \\
HDL-C & 2.351 & 0.213 & $-1.041,3.66$ & $\mathrm{~ns}$ \\
TG & 1.055 & 0.463 & $0.763,1.347$ & $\mathrm{~ns}$ \\
MDA & 12.092 & 1.15 & $9.913,14.271$ & $0.001^{* *}$ \\
Thiol & 23.662 & 0.225 & $8.295,39.029$ & $0.003^{* *}$ \\
TNF-a & 3.272 & 0.736 & $2.379,4.165$ & $0.001^{* *}$ \\
\hline
\end{tabular}

$B=$ un-standardized coefficient, Beta $=$ standardized coefficient, $95 \% \mathrm{Cl}=95 \%$ Confidence Interval 
levels tended to increase with the progression of the grade of NASH and grade of fibrosis, but these changes were not statistically significant.

\section{DISCUSSION}

In cases of non-alcoholic steatohepatitis (NASH), it has been suggested that progression from simple steatosis to steatohepatitis and then advanced fibrosis is caused by 2 distinct events. Firstly, insulin resistance leads to accumulation of fat within hepatocytes, and secondly, mitochondrial reactive oxygen species cause lipid peroxidation, cytokine induction, and the induction of Fas ligand. The lipid peroxidation products malondialdehyde (MDA), 4-hydroxynonenal (HNE) and some cytokines (tumour necrosis factor-alpha (TNF- $\alpha$ ), transforming growth factor-beta (TGF- $B$ ) and interleukin-8 (IL-8) can start the inflammatory response in the liver which either directly causes cellular damage or draws the inflammatory cells to the liver parenchyma (19-22). Lipid peroxidation is probably the most important pathogenic mechanism in NASH, but other factors also likely contribute to the development of NASH either by enhancing lipid peroxidation or by directly stimulating fibrogenesis and the inflammatory response characteristic of NASH (4).

In our study, IRI and HOMA-IR were significantly higher in patients with NASH compared to the control group $(p=0.001$, Table 1) and these results agree with the other studies that suggested that insulin resistance was the core pathogenic mechanism underlying $\operatorname{NASH}(5,9)$. NASH patients in our study had higher values of BMI, FPG, TC, LDL-C $(p=0.001)$ and TG $(p=0.002)$ than control subjects (Table 1 ). These results agree with the other studies that linked obesity especially visceral type and diabetes with NASH. Visceral obesity in particular has been strongly associated with metabolic syndrome and NASH $(23,24)$.

Visceral fat promotes fatty liver disease by several mechanisms. Firstly, intra- abdominal fat provides an immediate source of free fatty acids that are delivered directly into the portal vein (24). Secondly, individuals with truncal obesity have extremely low levels of adiponectin and relatively high levels of TNF- a (25). In accordance with this, our study revealed a significantly higher level of TNF- $a$ in patients of NASH compared to control subjects $(p=0.001$, Table 1$)$. TNF- $a$ is known to activate intracellular signaling molecules, including stress related kinases such as Jun $\mathrm{N}$-terminal kinase and inhibitor kappa beta kinase beta, that make cells resistant to the actions of insulin (26). Adiponectin antagonizes both the production and activity of TNF- $\alpha$ (27-30). Therefore, TNF- $a$ actions are potentiated when adiponectin is scarce (31). In addition, TNF- $a$ itself inhibits adiponectin $(32,33)$. Adiponectin acts directly on hepatocytes to inhibit fatty acid synthesis and uptake while stimulating fatty acid oxidation $(34,35)$. Therefore, adiponectin itself also enhances hepatocyte sensitivity to insulin (36). The combination of low adiponectin and high TNF- a levels in the context of increased hepatic exposure to free fatty acids results in hepatic steatosis and severe hepatic insulin resistance (37).

Ferritin is a high molecular weight iron storage protein occurring mainly in the cells of the liver and reticuloendothelial system (38). Although serum ferritin levels could increase to a degree disproportionate to that of iron stores in some forms of inflammation, liver disease and increased red-cell turnover, it closely reflects the size of the total iron burden (39) and ferritin iron (40). In the present work, serum levels of ferritin and iron was found to be significantly higher in the patient's group of NASH than in the control group $(p=0.001$, Table 1). Moreover, serum ferritin had a significant positive correlation with BMI, ALT, AST, FPG, TG, total cholesterol, LDL-C, serum insulin and insulin resistance $(p=0.001$, Table 2). Our results are in agreement with Shira et al (9) and Mehmet et al (41). However, after adjustment for age, sex, BMI and HOMA-IR, serum ferritin still showed a significant positive correlation with ALT, FPG and total cholesterol $(p=0.001)$, but there was no significant correlation with AST, LDL-C, HDL-C or TG (Table 3).

The significant positive correlation of serum ferritin with insulin and insulin resistance (Table 2 ) suggests that hepatic iron or iron-induced oxidative stress is closely related to insulin resistance (42). It has been reported that serum ferritin level, a major determinant of NAFLD in apparently healthy obese individuals (43), is significantly correlated with the amount of visceral fat mass and hepatic steatosis (44). Furthermore, serum ferritin level has been reported to be significantly higher in NASH than that in simple steatosis, which may reflect increased hepatic iron overload and enhanced oxidative stress (45). In this respect, dietary restriction of calories, fat and iron leads to improvement of NAFLD and reduced serum ferritin levels appear to reduce oxi- 
dative stress in the liver (46). In the present work, we found that serum ferritin presented a significant positive correlation with serum TNF- $a(p=0.001$, Table 2$)$ even after adjustment for age, sex, BMI and HOMA-IR $(p=0.001$, Table 3$)$, which may indicate that the serum ferritin had a relation to the inflammatory and fibrotic process ongoing in the liver in cases of NASH.

The markers of oxidative stress in our study (MDA and thiol) were higher in NASH group of patients more than in control group $(\mathrm{p}=0.001$ and 0.01 , respectively, Table 1) and they showed a significant positive correlation with serum ferritin ( $p=0.001$, Table 2 ) even after adjustment for age, sex, BMI and HOMA-IR ( $p=0.001$ and 0.003 , respectively, Table 3 ), and these results agree with Bahcecioglu et al (47). Oxidative stress influences both glucose and iron metabolism. Oxidative stress induces both insulin resistance, by decreasing internalization of insulin and increased ferritin synthesis (48).

Fargion et al (49) documented that hyperferritinemia with normal transferrin saturation was a hallmark of a glucose and lipid metabolism disorder and that patients with increased serum ferritin and normal transferrin saturation, a mild iron overload and multiple coexisting metabolic alterations are at high risk of developing NASH. In addition, they observed no correlation between liver iron concentration and histological grade and stage within a group of patients with NASH. These findings agree with the results in our study in which there is no significant correlation of the serum iron level with either grade of NASH or fibrosis. The increase in ferritin level may be due to a synergestic induction of synthesis due to increased iron stores and hepatic steatosis. It is also possible that an increase in ferritin occurs as a result of acute phase response (8). The previous studies in addition to the present work strengthen the role of ferritin and iron in NASH and in according to these results, there is at least one study showed improvement in insulin sensitivity with the use of venesection in patients with NASH. Biweekly phlebotomy until serum ferritin concentration became lower than or equal to $30 \mathrm{pg} / \mathrm{ml}$ reduced mean serum ALT activity without a significant change of body weight, suggesting that iron reduction therapy by phlebotomy will be one of the promising therapies for NASH (50), although this approach cannot be implemented without extensive review.

There are several limitations applied to our study. First limitation was the small sample size. We planned to in- clude a larger number of cases, but unfortunately many patients refused to give liver biopsy, so they were excluded from the study. The proposed design of our study was to admit the patients in our hospital with the aim to be under medical supervision for one day with no specific cause of admission, but actually many of our patients refused admission, so they were taken from the outpatient clinic. Of course, we know that the results of the present study are confirmatory to previously published information, but we think that the pattern of liver diseases including NASH which is related mainly to metabolic syndrome may be different in different populations and up to our knowledge, this is the first study for relation of serum ferritin to NASH in Egyptian population. Secondly a single measurement of serum ferritin may not be representative of the 'true' exposure to stored iron (if e.g. recent blood loss or recent use of aspirin has occurred). Thus, an optimal indicator of exposure would be serial measurements of the ferritin level over a given period of time. Third, although measurement of insulin resistance by the HOMA-IR index has been demonstrated to correlate with results obtained using the glucose clamp technique or minimal model analysis, its validity in different populations has never been tested. Fourth, in our study, it was not possible to measure hepatic iron content.

It has been suggested that NASH has multiple pathogenic mechanisms including insulin resistance, oxidative stress, mitochondrial dysfunction and cytokines production. Serum ferritin is correlated with oxidative stress and insulin resistance in cases of NASH. The elevated level of serum ferritin and its role in the pathogenesis of NASH was the basis of the idea for dietary restriction of iron and iron reduction therapies like venesection in the treatment of NASH, but this needs to be tried in a large population studies before it is established as an approved line of treatment.

\section{REFERENCES}

1. Marchesini $G$, Bugianesi $E$, Forlani $G$, et al. Non-alcoholic fatty liver disease (NAFLD), steatohepatitis and the metabolic syndrome. Hepatology 2003;37:917-923.

2. Brunt $E$. Non-alcoholic fatty liver disease: definition, epidemiology, pathogenesis and management. Semin Liver Dis 2001;21:3-16.

3. Ludwig J, Viggiano TR, Mc Gill DB, et al. Non-alcoholic steatohepatitis. Mayo Clinic experiences with hitherto unnamed disease. Mayo Cli Proc 1980;53:434-438. 
4. Reid AE: Non-alcoholic steatohepatitis. Gastroenterology 2001;121:710-723.

5. Sanyal JA, Campbell-Sargent C, Mirshahi F, et al. Nonalcoholic steatohepatitis: association of insulin resistance and mitochondrial abnormalities. Gastroenterology 2001;120:1183-1192.

6. Nakashima T, Sumida $Y$, Furutani $M$, et al: Elevation of serum thioredoxin levels in patients with Non-alcoholic steatohepatitis. Hepatol Res 2005; 33:135-137.

7. Diehl AM, Li HZ, YangSQ. Cytokines and the pathogenesis of Non-alcoholic steatohepatitis. Gut 2005;54:303-306.

8. Kemal A, Ali R, Muhsin K. The importance of iron and copper accumulation in the pathogenesis of non-alcoholic steatohepatitis. Turk J Gastroent 2003;14 (4):228-233.

9. Shira Z, Dorit N, Zamir H, et al. NAFLD and hyperinsulinemia are major determinants of serum ferritin levels. J Hepatol 2007;46(4):700-707.

10. Sumid Y, Yoshikawa T and Okanoue T: Role of hepatic iron in non-alcoholic steatohepatitis. Hepatology Research 2008; 39(3): 213-222.

11. Brunt E, Janney C, Di Bisceglie A, et al. Non-alcoholic steatohepatitis: a proposal for grading and staging the histological lesions. Am J Gastroent 1999;94:2467- 2474.

12. Report of the Expert Committee on the Diagnosis and Classification of Diabetes Mellitus. Diabetes Care 1997;20:1183-1197.

13. Wahlefeld AW.Triglyceride: determination after enzymatic hydrolysis . In Method of Enzymatic Alysis 1974; (ed H.U.Bergmyer ) pp 1831-1835. Academic Press, New York, NY.

14. Allian CA, Poon LS, Chan CGS, et al. Enzymatic determination of total serum cholesterol. Clin Chemist 1974;20:470-475.

15. Bachrik PS and Alerbs JJ. Precipitation methods for quantification of lipoprotein. In Method in Enzymology. 1986; Vol. 129 (eds J.J.Albers \& J.P.Segrest), PP 78-100. Academic Press, London.

16. Hu ML. Measurement of thiol groups and glutathione in plasma. Methods Enzymol 1998;233:380-385.

17. Drapper H, Hadley M. Assessment of MDA. Method. Enzymol 1990;186:421-431.

18. Mathews DR, Hosker JP, Rudenski AS, et al. Homeostasis model assessment: insulin resistance and beta-cell function from fasting plasma glucose and insulin concentration in man. Diabetologia 1985;28:412-429.

19. Citturi S and Farrell GC. Ethiopathogenesis of non-alcoholic steatohepatitis. Semin Liver Dis 2001;21:27-41.

20. Mc Cullough AJ. Update on NAFLD. J Clin Gastroent 2002;34(3):255-262.

21. Day CP, James OEW. Steatohepatitis: a tale of two 口hits" ? Gasroent 1998;114: 842-45.

22. Angulo P. Medical Progress: Non-alcoholic fatty liver disease. N Eng J Med 2002;346(16):1221-1231.
23. Katsuki A, Sumida $Y$, Urakawa $H$, et al. Increased visceral fat \& serum levels of triglyceride are associated with insulin resistance in Japanese metabolically obese, normal weight subjects with normal glucose tolerance. Diabetes Care 2003;26:2341- 2344.

24. Kelly DE, Mc Kolanis TM, Hegazi RA, et al. Fatty liver in type 2 diabetes mellitus: relation to regional adiposity, fatty acids and insulin resistance. Am J Physiol Endocrin Metab 2003;285:E 906-916.

25. Misra A, Garg A. Clinical features and metabolic derangements in acquired generalized lipodystrophy: case reports and review of the literature. Medicine 2003; 82:129-146.

26. Hirosumi J, Tuncman $G$, Chang $L$, et al.A central role for JNK in obesity and insulin resistance. Nature 2002;420:333-336.

27. Ruan $H$, Lodish HF. Insulin resistance in adipose tissue: direct and indirect effects of TNF- a. Cytokine Growth Factor Rev 2003; 14:447-455.

28. Fernandez-Real JM, Lopez-Bermejo A, Casamitjana R, et al. Novel interactions of adiponectin with the endocrine system and inflammatory parameters. J Clin Endocrin Metab 2003;88:2714-2718.

29. Ouchi N, Kihara S, Arita Y, et al. Adiponectin, an adipocyte-derived plasma protein, inhibits endothelial NFKappa B signaling through a CAMP-dependent pathway. Circulation 2000;102:1296-1301.

30. Yokota T, Oritani K, Takahashi I, et al. Adiponectin, a new member of the family of soluble defense collagens, negatively regulates the growth of myelmonocytic progenitors and the functions of macrophages. Blood 2000;96:1723 -1732 .

31. Kern PA, Di Gregorio GB, Lu T, et al: Adiponectin expression from human adipose tissue: relation to obesity, insulin resistance and TNF- a expression. Diabetes 2003; 52: 1779-1785.

32. Bruun JM, Lihn AS, Verdich C, et al. Regulation of adiponectin by adipose tissue-derived cytokines: in vivo and in vitro investigations in humans. Am J Physiol Endocrin Metab 2003;285:E 527-E 533.

33. Arner $P$. The adipocyte in insulin resistance: key molecules and the impact of the thiazolidinediones. Trends Endocrinol.Metab 2003;14:137-145.

34. Yamauchi T, Kamon J, Minokoshi Y, et al. Adiponectin stimulates glucose utilization and fatty acid oxidation by activating AMP-activated protein kinase. Nat Med 2002;8:1288-1295.

35. Yamauchi T, Kamon J, Ito $Y$, et al. Cloning of adiponectin receptors that mediate antidiabetic metabolic effects. Nature 2003;423:762-769.

36. Stephan N and Stumvoll M. Adiponectin - its role in metabolism and beyond. Horm Metab Res2002;34:469-474.

37. Yamauchi T, Kamon J, Waki $\mathrm{H}$, et al. The fat-derived hormone adiponectin reverses insulin resistance associated with both lipoatrophy and obesity. Nat Med 2001;7:941946.

38. Lipschitz DA, Cook JD, Finch A. Clinical evaluation of se- 
rum ferritin as an index of iron stores. New Eng $\mathrm{J}$ Med 1974;290:1213-1216.

39. Prieto J, Barry M, Sherlock S. Serum ferritin in patients with iron overload and with acute and chronic liver diseases. Gastroent 1975;68:525-533.

40. Nielsen $P$, Gunther $U$, Durken $M$, et al. Serum ferritin, iron overload and liver damage: Correlation to body iron stores and diagnostic relevance. J Lab Clin Med 2000;135:413-418.

41. Mehmet K, Seyithan T, Cemil M, et al. Serum levels of acute phase proteins in patients with Non-alcoholic steatohepatitis. Turk J Gastroent 2003;14(1):112- 120.

42. Dandona $P$, Hussain MAM, Varghese $Z$, et al. Insulin resistance and iron overload. Ann Clin Biochem 1983;20:77-79.

43. Hsiao TJ, Chen JC, Wang JD. Insulin resistance and ferritin as major determinants of NAFLD in apparently healthy obese patients. Int J Obesity Relat Metab Disord 2004;28:167-172.

44. Iwasaki T, Nakajima A, Yoneda M, et al. Serum ferritin is associated with visceral fat area and subcutaneous fat area. Diabetes Care 2005;28:2486-2491.
45. Sumida $Y$, Nakashima $T$, Yoh $T$, et al. Serum thioredoxin levels as a predictor steatohepatitis in patients with NAFLD. J Hepatol 2003;38: 32-38.

46. Yamamto $M$, Iwasa $M$, Iwata $K$, et al. Restriction of dietary calories, fat and iron improves NAFLD. J Gastroent Hepatol 2007;22(4):498- 503.

47. Bahcecioglu $I H$, Yalniz $M$, lihan $N$, et al. Levels of serum vitamin A, alpha-tocopherpl and malondialdehyde in patients with Non-alcoholic steatohepatitis: relationship with histopathologic severity. Internat J Clin Practice 2004;59(3):318-323.

48. Bertelsen M, Nggard EE, Carrier MJ. Oxidative stress impairs insulin internalization in endothelial cells in vitro. Diabetologia 2001;44:605-613.

49. Fargion S, Mattioli $M$, Fracanzani $A L$, et al. Hyperferritinemia, iron overload and multiple metabolic alterations identify patients at risk for Non-alcoholic steatohepatitis. Am J Gastroent 200;96: 2448-2454.

50. Sumida $Y$, Kanemasa $K$, Fukumoto $K$, et al. Effect of iron reduction by phlebotomy in Japanese patients with Non-alcoholic steatohepatitis: A pilot study. Hepatol Res 2006;36:315-21. 